\title{
El Palau de la Música de Barcelona, un reflejo de las inquietudes culturales de la burguesía catalana
}

\author{
JOAQUIN M. a PIÑEIRO BLANCA
}

Barcelona vive, en los años finales del siglo XIX, uno de los períodos más brillantes de su historia: el floreciente clima económico, concretado en el desarrollo de su industria textil, propició que la burguesía asentada en la ciudad disfrutase de uno de sus momentos más prósperos. Esto no podía por menos que afectar de un modo determinante a todos los órdenes de la vida barcelonesa (1). El ferrocarril estrechaba los lazos de unión de las principales ciudades de Cataluña desde 1848, ampliando así enormemente el campo de influencia de Barcelona a partir de aquellos años. En 1859 se aprobó el proyecto de ensanche de la ciudad presentado por Idelfonso Cerdá, que salió adelante por Real Decreto, ignorando el concurso que a tal efecto había convocado el Ayuntamiento de Barcelona y en el que había obtenido el primer premio el arquitecto Antonio Rovira i Trias. Al amparo de este ambicioso proyecto floreció en la ciudad una campaña de derribo de viejos edificios y de construcción de otros nuevos; este proceso acogió la materialización de un nuevo estilo arquitectónico en las calles de Barcelona: el Modernismo (2). El Palau de la Música fue una de las obras nacidas en tales circunstancias: A éste acompañaron el edificio de la Universidad, el Seminario Conciliar, el Mercado de San Antonio y la Fábrica Batlló; y eran reconstruidos el Monasterio de Ripoll y el Gran Teatro del Liceo. La nómina de arquitectos era de gran prestigio: Elies Rogent, Rafael Guastavino, Oriol Mestres, Antonio Rovira i Trias, José María Cornet y José Fontsere i Mestres.

(1) JUTGLAR, A.: "Historia crítica de la burguesía en Cataiuña". Barcelona, 1983. pp. 83 y ss.

(2) Para responder a esta fuerte demanda constructiva, se crea en 1871 la Escuela de Arquitectura de Barcelona. 
El punto culminante de la expansión cultural barcelonesa tuvo lugar a raíz de la celebración de la Exposición Universal de 1888 (3). En ella tuvo un especial protagonismo el futuro arquitecto del Palau de la Música: Lluis Doménech i Montaner (Barcelona, 1850-1923). Este edificó para el evento el Gran Hotel y el Café-Restaurante de la Exposición ("El Castillo de los Tres Dragones"), consagrándose así de forma definitiva. La importancia de estas obras es grande al ser consideradas el punto de partida del Modernismo arquitectónico en Barcelona (aunque pocos años antes, Antonio Gaudí sentara parte de los presupuestos estéticos del nuevo estilo en la Casa Vicens). El eclecticismo artístico dominante hasta ese momento comenzó a ser abandonado, y la oleada de nuevas construcciones permitidas por el ensanche fueron fieles seguidoras del Modernismo (4). Simultáneamente al cultivo de este nuevo movimiento arquitectónico, el mundo de las letras, de la música y de la pintura y la escultura fueron asimismo testigos de un período brillante bajo el cobijo de los presupuestos estéticos del nuevo estilo: el autor dramático postromántico Angel Guimerá; el poeta Alexandre de Riquer; los pintores Ramón Casas, Santiago Rusiñol, Sebastián Junyent y Hermenegildo Anglada i Camarasa; los escultores José Llimona, Miguel Blay, Enrique Clarassó y Eusebio Arnai; y los compositores Felipe Pedrell, Amadeo Vives, Francisco Tárrega, Pablo Casals y Enrique Granados. Este movimiento cultural, delimitado y caracterizado con tanta precisión, no fue sino una respuesta más del Catalanismo político que entonces iniciaba su andadura, y que buscaba constantemente elementos que esgrimir frente al Gobierno de Madrid (5).

\section{EL NACIMIENTO DEL EDIFICIO DEL PALAU DE LA MUSICA. CATALANISMO Y WAGNERIANISMO}

La burguesía barcelonesa, inquieta intelectualmente y con la suficiente tranquilidad económica como para desarrollar sus inclinaciones culturales, otorgaba lugar preferente en ellas a la música y todas sus

(3) ALBERTIN, S.: "El Republicanismo Catalán y la Restauración Monárquica (1875-1923)". Barcelona, 1973. pp. 102 y ss.

(4) CARBONELL, J.; "Breve semblanza de una época". En: "Antoni Gaudí (1852-1926)". Barcelona, 1985. pp. 221-231.

(5) El primer grupo político catalanista fue el Centre Catalá, fundado en 1885 por Valentí Almirall. En 1891 se constituye la Unió Catalanista, con el propósito de coordinar las distintas entidades adscritas a esta ideología repartidas por las distintas comarcas de Cataluña. En el Ayuntamiento de Manresa tuvo lugar la primera reunión del grupo, de la que salió una propuesta de diecisiete bases para la creación de la Constitución Regional Catalana. 
manifestaciones (6). El próspero y brillante ambiente musical de la ciudad fue decreciendo en importancia según se iba acercando el fin de siglo, y fue otro factor propiciador para la construcción del edificio del Palau. Por entonces, Barcelona estaba sufriendo las oleadas de "wagnerianismo" más fuertes de su historia: en estos años se libraban en Europa los combates en pro y en contra de la música de Ricardo Wagner. El apasionado fenómeno había removido las aguas del mundo de la ópera y amenazaba, no sólo con derrocar al repertorio italiano de su, hasta ahora, firme trono, sino con modificar, desde su base, los presupuestos teóricos en los que se basaba el género operístico como tal (7). Bastante había retrasado la difusión y consagración de la obra de Wagner el fracaso del "Tannhäuser" en Paris, en 1861: la crítica desfavorable fue aceptada en todo el mundo casi como un dogma de fe. Al iniciarse la Restauración en España, el legado artístico de Wagner era aún casi desconocido en Barcelona. Pero, tras la fundación, en 1871, de una primera Sociedad Wagner (8), la difusión de su música se convirtió en un fenómeno cultural de primera magnitud, llegando finalmente a conquistar a casi todos los aficionados de la ciudad, aunque, desde luego, no se abandonasen del todo las polémicas entre italianistas o tradicionalistas y wagnerianos. Los primeros propagadores de la música del compositor alemán en Barcelona fueron el doctor José de Letamendi y su discípulo Joaquín Marsillach. Ellos utilizaron como medio para dar a conocer las excelencias de las composiciones del músico de Leipzig, la interpretación de fragmentos de sus óperas en transcripciones para piano en los salones y establecimientos que eran claves en el desarrollo de la vida cultural de la ciudad (9). La que muchos llamaron "la música del porvenir", pronto comenzó a afianzarse en los gustos de los barceloneses, hasta culminar con el estreno, en el Teatro Principal, de la primera ópera de Wagner representada en la ciudad: "Lohengrin". Esto tuvo lugar la noche del 17 de mayo de 1882. El haber elegido esta pieza para darlo a conocer a un

(6) En 1845 fue construido el actual edificio del Gran Teatro del Liceo. De ese año, Barcelona desarrollará una amplia actividad musical, especialmente operística, paralela en importancia a la que entonces se tenía en el resto de Europa. Por establecer unos ejemplos: "Don Carlo", la ópera de Giuseppe Verdi estrenada en París en 1867, fue puesta en escena por primera vez en el Liceo tan sólo tres años más tarde. O "Adriana Lecouvreur", de Francesco Cilea, un año después de su estreno, en 1903.

ALIER, R.: "Gran Teatro del Liceo". Barcelona, 1986. pp. 17-33.

(7) GAUTHIER, A.: "Wagner". Madrid, 1984. pp. 112-122.

(8) Entre los primeros miembros de la Sociedad Wagner, fundada en Barcelona en 1871, se encontraban nombres de la importancia de Felipe Pedrell y Claudio Martínez Imbert.

(9) ALIER, R.: op. cit. pp. 35-36; 39-42. 
público tan italianizado, se debió, en gran parte, al carácter intermedio de esta obra entre el estilo tradicional y los nuevos conceptos introducidos por Wagner, aún en proceso de gestación. La impresión inicial fue positiva, aunque no dejaron, por supuesto, de estar presentes las críticas de los más tradicionalistas. Al amparo de este tímido éxito, se fueron dando a conocer de forma sucesiva el resto de sus títulos menos innovadores (y, por lo tanto, más "digestivos" para el público): "El Holandés Errante", en 1885, y "Tannhäuser", en 1887, ambos en el Gran Teatro del Liceo. Las filas de wagnerianos se hallaban a estas alturas bien nutridas, y fue la corriente Modernista la que las terminó de llenar: los sucesivos estrenos en el Liceo de "La Walkiria" (1899), "Tristán e Isolda" (1899), "Siegfried" (1900), "El Ocaso de los Dioses" (1901), "Los Maestros Cantores de Nuremberg" (1905), la "Tetralogía" completa (Oro del Rhin, Walkiria, Siegfried y Ocaso de los Dioses) (1910) y "Parsifal" (1913) culminaron el proceso. El ciclo se completó con la fundación de la Associació Wagneriana en octubre de 1901.

Como hemos apuntado, el Wagnerismo y el Modernismo en Barcelona se presentaron fuertemente unidos (10): no existía en la ciudad un modernista que no fuese también apasionadamente wagneriano, y todo ello iba vinculado, además, a un creciente empuje del Catalanismo literario, artístico y político, como hemos comentado. Este veía en el Modernismo europeo el modelo a seguir, y en la cultura germánica el ejemplo que cabía imitar para no caer en los supuestos errores del empobrecido imperio español que, por estos años, iba a perder sus últimas posesiones de ultramar. Los postulados previos tenían la virtud de parecer atractivos en un momento en el que el Estado español se debatía en tan honda crisis; no es de extrañar, pues, que todo ello tuviese su influencia en los distintos campos de la cultura, incluidos el musical y el arquitectónico (11).

En este contexto cultural se inicia el proceso de construcción del Palau de la Música en pleno centro del barrio antiguo de Barcelona. El edificio es encargado por la Junta Directiva del Orfeó Catalá a Lluis Doménech i Montaner (12), quien dio comienzo a las obras en 1905.

(10) TUÑON DE LARA, M.: "Medio siglo de cultura española (1885-1936)". Madrid, 1973. pp. 15 y ss.

(11) MATEU, M.; VIÑAMATA, A.: "Wagnerismo y Modernismo en Cataluña". "Ritmo" nº 533, mayo de 1983. Madrid.

(12) Lluis Doménech i Montaner (Barcelona, 1850-1923) venía precedido de un considerable prestigio, propiciado por el gran éxito alcanzado con algunas de sus obras, tales como el edificio de la Editorial Montaner y Simón, en la misma Barcelona, o por el palacio del Marqués de Comillas, en Santander. En estos años realizaba el hospital barcelonés de San 
Estas se alargarian hasta 1908 (13). El hecho de haber resultado elegido este arquitecto por parte de los promotores de la construcción del Palau de la Música, nos proporciona una pista sobre el talante abierto de éstos a las últimas novedades artísticas europeas, sin bien esta postura no era extraña en la ciudad. Como veremos, el Palau no participa de casi ninguna de las características tradicionales de una sala de conciertos.

Arropado por el renacimiento cultural de Barcelona durante la celebración de la Exposición Universal de 1888, se constituye el 6 de septiembre de 1891 el Orfeó Catalá gracias a la iniciativa de los maestros Lluis Millet y Amadeo Vives. (14). Es esta entidad la que propicia, gracias a lo sólido de su organización, la construcción del Palau de la Música para ser utilizado como su sede oficial, justo en el momento en el que su trayectoria cultural había llegado a su punto más alto. En el año de la inauguración del edificio, 1908, sus treinta y siete socios iniciales se habían visto aumentados hasta la importante cifra de dos mil doscientos. Estos, en su mayoría, pertenecían a la pequeña y mediana burguesía, lo que proporcionaba a la asociación miembros con la suficiente capacidad económica como para cubrir el emprésito de seiscientas mil pesetas con el que se costeó el edificio, a través de la compra de obligaciones de quinientas y cien pesetas, amortizables en cuarenta y dos años.

La inauguración y los cimientos ideológicos que propiciaron esta iniciativa, daban al Palau de la Música unas notas distintivas que le hacían sobrepasar el concepto de sede social o sala de conciertos. La simbología decorativa del edificio y el programa del concierto inaugu-

Pablo, empresa que había dado comienzo en 1902, y que no finalizaría él, sino su hijo, en 1910. Las obras del Palau serían simultaneadas con las de éste. Doménech i Montaner fue director de la Escuela Superior de Arquitectura de Barcelona, fundó y dirigió la revista "Artes y Letras" (1882-1883) y fue autor de tratados como "Historia y arquitectura del Monasterio de Poblet" o "Nobiliari Catalá". Inaugura lo que se ha venido a llamar la "Corriente Racionalista" del Modernismo catalán. No obstante, sus comienzos fueron inseguros, con abundantes rasgos de otros estilos, es decir, en una posición más cercana al Eclecticismo que al Modernismo propiamente dicho (VV.AA.: "Estilos y tendencias del arte occiderital". Barcelona, 1973. pp. 38-51). Un ejemplo de ello lo constituye el Café-Restaurante de la Exposición Universal de 1888, pero su hospital de San Pablo, el Palau de la Música y la Casa de Lleó deben adscribirse plenamente al movimiento modernista.

(13) QUERALT DEL HIERRO, M. a P.: "El Orfeó Catalá”. En “Historia y Vida” no 175. Barcelona, 1968. pp. 50-63.

(14) Lluis Millet i Pages (Barcelona, 1867-1941), musicólogo, pianista y director de masas corales en Cataluña, alcanzaría su justa fama al frente del Orfeó Catalá, que dirigió desde su fundación hasta su muerte.

Amadeo Vives (Barcelona, 1871-1932), compositor de óperas y zarzuelas, autor de algunas tan célebres como "Doña Francisquita", "Bohemios", "Maruxa", "La Generala" y "La Villana". 
ral hablan por sí solos de una filosofía que pretendía ser, al mismo tiempo, catalanista y universalista. (15). Entre sus socios se encontraron elementos destacados del nacionalismo en Cataluña como fueron: Angel Guimerá, Narcís Oller, Joan Maragall, Josep M. Folch i Torras, Higini Anglés, Enrique Granados, Enrique Prat de la Riba, Duran i Ventosa, Puig i Cadafalch, Verdaguer i Callis, Francesc Cambó, ... Ellos eran también miembros de destacadas familias burguesas catalanas. Los últimos cinco nombres citados nos proporcionaban, además, otro elemento de vinculación del Orfeó con el catalanismo, al pertenecer éstos al cuadro dirigente de la Lliga Regionalista y ser formuladores teóricos de este movimiento político (16). Es evidente que si bien no existió un nexo formal con este partido, por proximidades ideológicas, se encontraba la formación coral muy cerca de éste. La música debía actuar como detonante de fuertes sentimientos patrióticos. Eran unos momentos en los que un símbolo podía alcanzar mucho más poder, de cara a la concienciación popular, que muchos de los discursos políticos, por brillantes que éstos fuesen. Esta fue una circunstancia que no escapó ni a los fundadores ni a aquellos que colaboraron posteriormente con esta entidad musical.

\section{EL EDIFICIO DEL PALAU DE LA MUSICA Y LAS CLAVES SIMBOLICAS REFLEJADAS EN SU DECORACION}

Fuera de Cataluña, el Modernismo español apenas dejó manifestaciones de importancia, y fue Barcelona la ciudad que aglutinó y concentró las mejores y más variadas muestras del movimiento artístico que nos ocupa. Alli el "nuevo estilo" marcó una etapa de extraordinario esplendor cultural, como ya habíamos apuntado, coincidente con el auge económico de la ciudad. Al contrario de lo que había venido sucediendo en otras corrientes artísticas del pasado, en ésta es solamente la arquitectura la que marca las pautas a seguir y la que cualitativa y cuantitativamente alcanza por tanto el mayor grado de desarrollo; si bien no debemos olvidar que ésta llevó consigo un cultivo importante de una serie de artes menores que nunca habían sido, como ahora, tan dependientes de la arquitectura: vidrieras, mosaicos, cerámicas, junto con pinturas y esculturas, cubren las estructuras inter-

(15) El concierto inaugural contó en su programa con obras de fuerte contenido catalanista, como "El cant de la Senyera" de Millet, "Els Xiquets de Valls" de Clavé y "La mare de Deu" de Nicolai.

(16) CASANOVAS, J.: "El modernismo en Cataluña". Barcelona, 1982. Tomo II. 
nas y externas de los edificios modernistas, desfigurando en gran parte de los casos sus auténticas líneas constructivas o siendo unos elementos configuradores tan importantes como los estructurales. Esta diferencia apreciativa depende tan sólo del punto de vista que tomemos para elaborar este análisis (17).

Los primeros pasos de la arquitectura modernista en España se dan en Barcelona en 1880, con la inauguración de la audaz y provocadora Casa Vicens de Antoni Gaudí. Esta fecha nos proporciona una clave: en el momento del inicio de las obras del Palau de la Música, en 1905 , la corriente artística se encontraba ya plenamente asimilada en la ciudad, con lo que, en este sentido, no resultaba tan novedoso como lo era veinte años atrás, pero, sin embargo, era un movimiento lo suficientemente joven como para otorgar aún la imagen de aperturista, de vanguardia cultural. Los promotores de la construcción del edificio encontraron así un mecenazgo audaz, pero seguro, y es éste, justamente, uno de los talantes omnipresentes en la burguesía barcelonesa de aquellos años (18).

Doménech i Montaner concibe el edificio como un todo global, de tal modo que todas sus partes estén estrechamente relacionadas, participando así de una de las características más definitorias del estilo modernista (19). El arquitecto utiliza una ingeniosa estructura de hierro, posiblemente por vez primera en Europa en usos no industriales, en la que se plasma, aunque de modo muy libre, el modelo de lo que se entendía que debía ser el destinado a una sala de conciertos: un gran patio de butacas de forma ovalada, truncada ésta por el escenario y el foso de la orquesta. Sin embargo se ofrece una solución nueva en el palcoscenio, al recorrer el segundo piso de palcos su parte posterior y al carecer de telón. Con ello simplemente se intentaba conseguir una mayor integración del público en él; se hallaba, pues, liberado del carácter cerrado y cuadrangular que caracteriza los escenarios de tipo convencional. En la fachada se introducen igualmente una serie de innovaciones con respecto a lo que se había venido dando hasta ese momento: la visión frontal, grandilocuente, con varias arcadas de acceso y que, en definitiva, había venido constituyendo un anticipo de lo que eran las estáticas y majestuosas estructuras internas de los teatros

(17) VV.AA.; "Las fuentes de la arquitectura moderna en el siglo XIX". Barcelona, 1970. Tomo XIX, pp. 24-70.

(18) MUNIESA, B.: "La burguesía catalana ante la II República: el triunfo de Wagner sobre Verdi". Barcelona, 1986. pp. 65-71.

(19) BOHIGAS, O.; "Reseña y catálogo de la arquitectura modernista". Barcelona, 1973. Tomo I, pp. 38-51. 
decimonónicos, abre paso a una versión totalmente libre, que abandona esa concepción tradicional al situar la entrada principal en uno de los ángulos del edificio, y con unas disposiciones espaciales que en nada anuncian las distribuciones internas de la construcción. Pero, de entre todas sus originalidades, la que sin duda resulta más llamativa es el cerramiento con vidrio de la estructura de hierro de la fábrica, proporcionando una luminosidad natural al conjunto que no encuentra precedentes en una sala de música. Una gran linterna ilumina focalmente el espacio escénico. Si algún reparo hubiese que poner al proyecto, reparos relativos naturalmente, éste sería el de la ocultación de la original estructura de hierro bajo la hojaresca decorativa, que es, por otro lado, la que nos resulta hoy más expresiva para intuir, en sus temas y motivos, las inquietudes y gustos musicales de la burguesía barcelonesa en los años finales del cambio de siglo (20).

Las escenas de fuerte carga alegórica y simbólica se mezclan con los personajes operísticos más queridos y con los retratos de los compositores más admirados, con una especial predisposición, naturalmente, por todo lo wagneriano (21): los escultores Pablo Gargallo y Eusebio Arnau y el mosaísta Bru, fueron distribuyendo en toda la superficie decorada del edificio una serie de detalles que inexcusablemente hablan del compositor alemán. Sobre el techo de la sala, entre el entramado de cerámica y vidrio, aparece escrito el nombre de Wagner; su busto en piedra preside una de las fachadas laterales; en el ala derecha del proscenio, sobre el órgano, Gargallo esculpió su famoso grupo de la Cabalgata de las Walkirias; ... la enumeración de estos motivos en su integridad podría resultar eterna. Pero aunque estas evidentes referencias no estuviesen presentes, todo el Palau de la Música podría sentirse como una gran ópera wagneriana, una síntesis en la que convergen todas las artes al servicio de la última forma arquitectónica, al igual que palabra, acción, resultado escénico y música se aglutinan en los dramas musicales de Wagner. Wagner y Doménech participan, en este sentido, del mismo concepto de "obra de arte total".

La sala queda dominada, igualmente, por dos alegorías pétreas que quisieron simbolizar la canción catalana y la canción universal, presididas respectivamente por los bustos de Clavé, el alma mater del Orfeó Catalá, y de Beethoven, quedando nuevamente patentes los sentimientos catalanistas de los promotores del edificio. Este espíritu

(20) BOHIGAS, O.: op. cit. pP. 51 y ss.

(21) MATEU, M.; VIÑAMATA, A.: op. cit. 
se encuentra igualmente vivo en el gran grupo escultórico que centra la esquina del edificio, sobre la entrada principal: su autor, Miguel Blay (22); representó la música popular catalana, en forma de muchacha, protegida por un San Jorge armado como patrón de Cataluña, aunque por su iconografía pareciese más bien el Lohengrin wagneriano.

Toda la extraordinaria suntuosidad del conjunto puede bien ser un claro instrumento de deducción del gran poder económico de la burguesía bajo cuyos auspicios fue construido, además de permitir adivinar cuáles fueron las líneas maestras de sus inquietudes culturales e, incluso, nacionalistas. El movimiento modernista creó sus propias estructuras musicales (23): el Orfeó Catalana, la coral de Catalunya Nova, la Revista Musical Catalana (1904-1936) y el edificio del Palau de la Música. Con todos estos nuevos elementos, la vida concertística de Barcelona se incorporó de manera definitiva a la europea, constituyendo el Palau la cumbre de este proceso. (24). En él se han mezclado admirablemente los anhelos culturales y el auge económico de una determinada clase social, los alardes arquitectónicos y decorativos del estilo modernista en su fase final y más extremista, y el impulso brillante de la vida musical de una ciudad, Barcelona.

\section{BIBLIOGRAFIA}

ALBERTIN, S.: "El Republicanismo Catalán y la Restauración Monárquica (1875-1923)". Barcelona, 1973.

ALIER, R.: "El Gran Teatro del Liceo". Barcelona, 1986.

BOHIGAS, O.: "Reseña y catálogo de la arquitectura Modernista". Barcelona, 1973.

CARBONELL, J.; "Breve semblanza de una época". En: "Antonio Gaudí (1852-1926)". Barcelona, 1985.

CASANOVAS, J.: "El Modernismo en Cataluña: Orfeó Catalá y los coros Clavé". Barcelona, 1982.

FERNANDEZ CID, M.: "Cien años de Teatro Musical en España". Madrid, 1975.

GAUTHIER, A.: "Wagner". Madrid, 1984.

JUTGLAR, A.: "Historia crítica de la burguesía en Cataluña". Barcelona, 1983.

(22) QUERALD DEL HIERRO, M. P.: op. cit. pp. 50-63.

(23) FERNANDEZ CID, A.: "Cien años de Teatro Musical en España". Madrid, 1975. pp. 52 y ss.

(24) No nos referimos a las actividades operísticas que, desde la primera temporada del Gran Teatro del Liceo en 1847, se encontraban entre las más importantes de Europa. Allí cantaron todos los intérpretes legendarios del pasado siglo, desde María Malibrán, Giulia Grisi, Adelina Patti, Giuditta Pasta, hasta Julián Gayarre, Francisco Viñas, Hipólito Lázaro y María Barrientos. ALIER, R.: op. cit. pp. 36-38; 40-42. 
MATEU, M.; VIÑAMATA, A.: "Wagnerianismo y Modernismo en Cataluña". Ritmo no 533. Madrid, mayo 1983.

MUNIESA, B.: "La burguesía catalana ante la II República; el triunfo de Wagner sobre Verdi". Barcelona, 1986.

QUERALT DEL HIERRO, M. a P.: "El Orfeó Catalá". Historia y Vida nº 175. Barcelona, 1968.

TUÑON DE LARA, M.: "Medio siglo de cultura española (1885-1936)". Madrid, 1973.

VV.AA.: "Las fuentes de la arquitectura moderna en el siglo XIX". Barcelona, 1970. Tomo XIX.

VV.AA.: "Estilos y tendencias del arte occidental". Barcelona, 1973. 